\title{
Exposure Modeling of Traffic and Wood Combustion Emissions in Northern Sweden
}

\section{Application of the Airviro Air Quality Management System}

\author{
Lars Gidhagen ", Cecilia Bennet, David Segersson, and Gunnar Omstedt \\ Swedish Meteorological and Hydrological Institute, Norrköping, Sweden \\ \{lars.gidhagen, cecilia.bennet, david.segersson, \\ gunnar.omstedt\} @smhi.se
}

\begin{abstract}
Traffic and residential wood combustion (rwc) constitute the two dominating local sources to fine particulate matter PM2.5 concentration levels in Sweden. In order to meet the authorities' requirements of air quality assessments, a national modelling system SIMAIR has been developed. The system is based on the commercial Airviro air quality management software, a three tier client/server/web system which includes modules for measurement data collection, emission databases and dispersion models with very high performance in terms of data access and model execution. The technical characteristics of Airviro databases and models have facilitated web based national air quality systems, of which some examples are given.

The present Airviro/SIMAIR application had the objective to assess the impact of rwc in three urbanized areas in northern Sweden. The Airviro Scenario module was used to determine exposure and health impact of the rwc contribution. The estimated mortality due to PM2.5 concentrations from residential wood combustion is about 4 persons/year, which corresponds to approximately $0.4 \%$ of the total number of deaths (excluding accidents). Cities which have well established district heating facilities have a lower rwc use and a very different exposure to locally generated PM2.5. Umeå, one of the three areas in the study, is such a city. A similar assessment with impact only from traffic emissions shows an increase of 4.4 deaths for the Umeå population, while the impact of wood combustion in the city contributes with 2.5 deaths per year. The advantages of using the Airviro software in combination with annually updated databases for input data on the national scale, are summarized. The approach facilitates for municipal end users and non-meteorological professionals like epidemiologists to perform by themselves advanced dispersion simulations and health impact assessments.
\end{abstract}

Keywords: Airviro, dispersion modelling, residential wood combustion, PM2.5 health.

\section{Introduction}

Fine particles with diameter $<2.5 \mu \mathrm{m}$ (PM2.5) suspended in ambient air constitute a leading risk factor contributing to premature death [1,2]. In Sweden the most 
important local source is road traffic emitting particles generated both by combustion and by road wear and brake abrasion. Another important source is residential wood combustion (rwc) and people living in smaller cities with rwc are exposed to elevated PM2.5 levels. According to a recent health review [3] these rwc particles may have a similar effect on health as traffic combustion particles. Strong impact of wood combustion is common not only in northern Sweden but also considered to be a large and well spread source of PM2.5 in Europe [4].

To facilitate the supervision of local air pollution hot spots and allow urban planning where air pollution levels can be held below European and Swedish standards, the Swedish EPA, the Swedish National Road Administration and the Swedish Energy Agency jointly commissioned the development of the web tool SIMAIR [5,6]. SIMAIR is a coupled model system covering all Swedish regions and urbanized areas, where local authorities can assess the current status of air quality. The SIMAIR system is based on a commercial air quality management software used in many locations around the world, the Airviro system [7]. SIMAIR has most of the environmental and activity data required in dispersion modeling preloaded, e.g. the entire Swedish road network. For Sweden this gives possibilities of annual overviews of spatial and temporal variations in PM10, PM2.5, NO2, CO and benzene levels. The system has previously been used to simulate national exposure of particulate matter for a specific year (2004) [8]. The exposure was then related to self-reported health problems [9]. The Airviro software has also been used as a platform for an integrated climate change enabled Environmental Decision Support System (EDSS) [10]. Recent development of the Airviro system includes a module, Airviro Scenario, where the exposure on the entire population can be assessed with respect to health outcomes and economical costs for different air quality scenarios. In much this module bears a strong resemblance with U.S. EPAs BenMap system [11]. The present study describes how the Airviro software, including Airviro Scenario, has been used together with SIMAIR input data to assess the health impact of air pollution from residential wood burning and road traffic. We also discuss potential users to this health impact assessment tool.

\section{Software}

The Airviro system has been developed during more than 30 years, originally for powerful (at the time) work stations and then migrated to Linux servers, i.e. it did not raise from personal computer platforms. Its highly optimized databases assure a rapid access of time series, both point and field data, which has made it ideal for large regional and national systems. The principal and fully integrated functionalities of the Airviro system are

- data collection, storage, validation and presentation

- emission database for point, area, line and grid sources

- dispersion models 
Through requirements from users in Europe, Asia and Latin America there is now a great flexibility for users to select among e.g. some 20 data collection protocols and an extensive list of dispersion models including Airviro models for different scales and purposes as well as open-source models like AERMOD, CALPUFF and AUSTAL2000.

A strength of the Airviro system is the capacity to process very large emission inventories with a mix of individual sources and gridded emissions. Also, the integration with the time-series database allows the use of live data, such as continuous stack measurements, traffic flow measurements or ship movements to be described in near real-time. A specialized type emission source has been developed to represent ship emission sources, in which the movements of the ships are described based on the positions of the individual ships found in AIS (Automatic Identification System) data for the sea area of interest. By adding information on ship engine data from available sources, Airviro allows the emissions from ships to be described with high temporal and spatial resolution. The emission database for residential wood combustion presented in this paper is another example of an advanced emission model for a very large number of individual sources.

Current versions Airviro 3.2x is a three tier client / server / web system. It runs on Linux platforms but Red Hat, Fedora and CentOS Linux are the preferred operating systems. The clients normally run on PCs using Java JRE (run time plugin) compatible web browsers such as Internet Explorer and Firefox. The web server side is using lean CGI scripts and heavy programs written primarily in $\mathrm{C}$. The pages at the client side use html and java script and are built on the server. Some small applets written in Java are also used on the client side primarily for caching, maps and user interfaces that are too complex to be written using html and JavaScript. All models are written using FORTRAN.

The Airviro databases are based on the FairCom CTREE ${ }^{\mathrm{TM}}$ server version 4.3 or on proprietary solutions. Communication of data into and out of the Airviro databases is performed through ASCII or EXCEL interfaces, or through Web services using HTTP or HTTPS protocols. An OGC compliant service layer to access, interrogate, execute models and upload/download gridded time series in Airviro was developed as part of the EU FP7 project SUDPLAN [10].

The great flexibility of the Airviro system gives advantages to large applications. National monitoring databases in Singapore, UK, Estonia and Chile are operated by Airviro. In a current upgrade of the Singapore system data collection is extended to high resolution precipitation sensors and other climate instruments. Other countries like Estonia, Chile and Sweden also uses the data collection together with emission inventories and dispersion models on a national scale. Airviro has recently been implemented in Turkey to collect and quantify emissions from ship traffic in the Bosphorus straight and adjacent seas. Smaller systems are serving local authorities and industries in some 20 countries.

The flexibility and generality of the system has the drawback that it makes it complex to configure and new users often require support for setting up the system and fill it with useful information serving the purpose of air quality management (which is not only doing diagnostic work of how things are today, but also to be able to identify air 
pollution control actions and project their effects on future air quality as part of a planning procedure). While this is manageable for large and specialized institutions, it is for users in individual cities or industries a threshold that is sometimes difficult to overcome. This is why the SIMAIR system, to be described in the next section, has been developed. SIMAIR is basically a simplified Airviro interface where less experienced users can access the preloaded information required to execute dispersion models for whatever location within Sweden.

\section{$3 \quad$ Method}

Figure 1 gives an overview of the Air Quality Management system and the work flow required for an health impact assessment based on a given emission scenario.

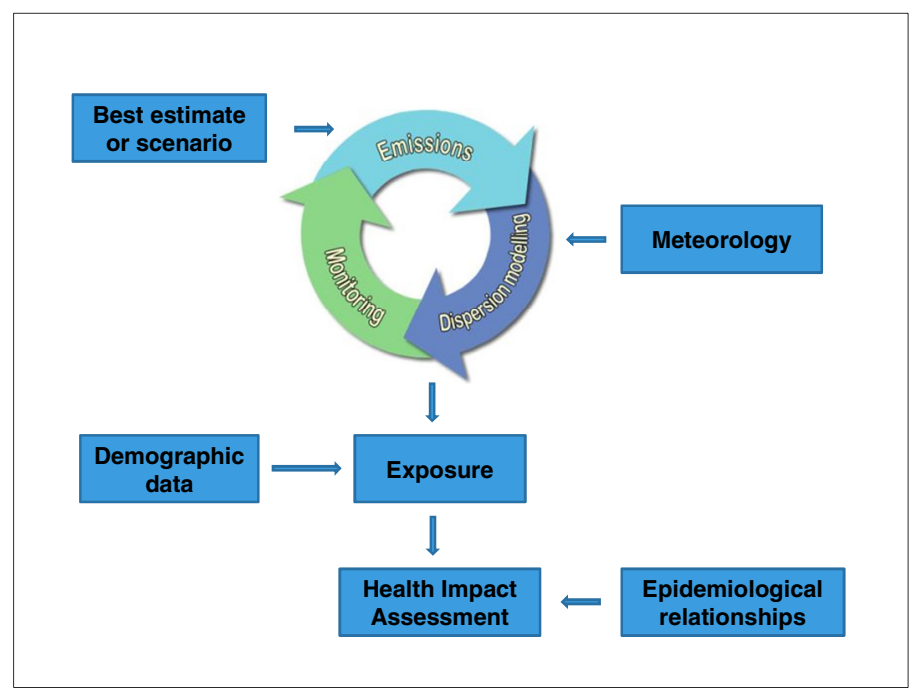

Fig. 1. Overview of data flows in the Airviro Air Quality Management System which involve four major modules: Emission Database, Dispersion models, Time series database/presentation/analyzing tool and the Scenario module with exposure assessments.

Starting point is the formulation of an emission scenario. Health effects can be based on absolute emissions, but it is also common to quantify the health benefits by comparing a scenario with reduced emissions to a reference (business-as-usual) scenario, i.e. health benefits achieved by a certain change in emissions. The results to be presented below will separately quantify the different health effects of the two largest local PM2.5 sources in Swedish cities (Figure 2). 

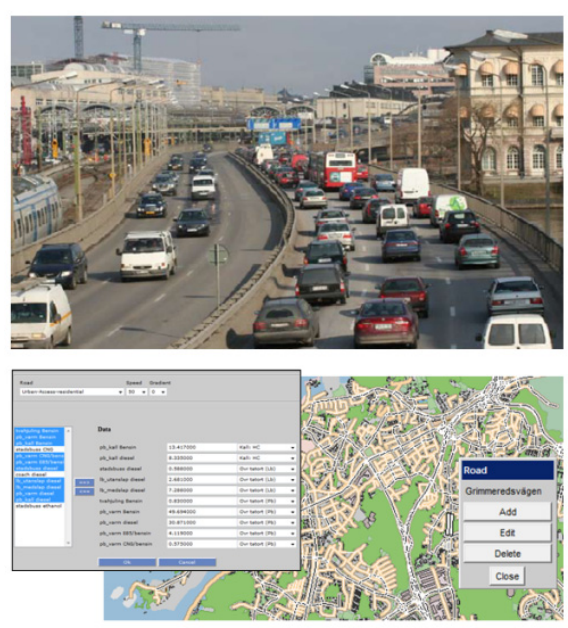
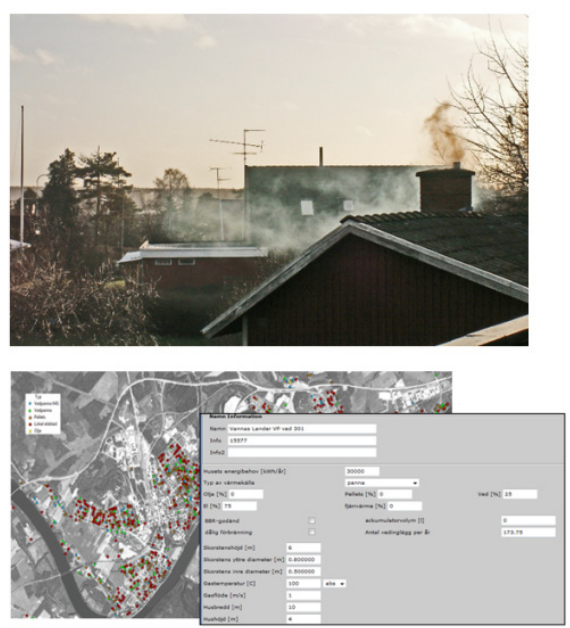

Fig. 2. The two major sources to PM2.5 pollution in Sweden and how the GUIs of the Airviro Emission Database can be used by local end-users to modify/update information of mobile sources (left) and residential wood combustion sources (right).

The next step is to feed the system with meteorological information, which can be taken - if available - directly from meteorological towers, from meteorological model output or from a combination (analyzed gridded data based on surface data, meteorological models, satellite and radar data routinely produced all over Sweden). With this it is possible to execute an appropriate dispersion model among those Gaussian and Eularian models available in Airviro. Population exposure calculations for entire cities are applications with tough requirements on performance, this since the rapid decrease in pollutant concentrations close to roads makes it necessary to describe the dispersion of pollutants with high spatial resolution. To facilitate these calculations, Airviro simulations can be made on a locally refined computational grid (Fig. 3).

Fig. 3. Example of refined computational grid - named quad grid - along a main highway. The original grid of $800 \times 800 \mathrm{~m}$ is refined to $50 \times 50 \mathrm{~m}$ along all roads where traffic emission intensity is above a specified threshold. For this example the number of grid cells are only $4.13 \%$ of that of a regular grid with 50x50 m resolution.

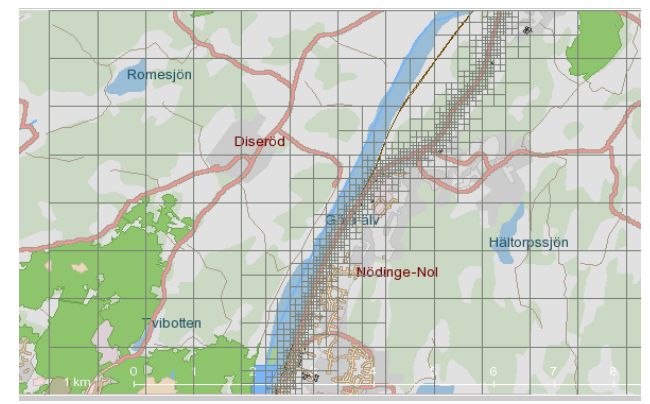


Since all models produce hourly time series of pollution concentrations, it is possible to evaluate model output through a comparison with monitor data. Such quality assurance comparisons should always be performed when measured concentrations are at hand. It is common to find rather severe errors in the emission description, calling for a new round in the emission-dispersion-monitoring cycle of Fig. 1.

When confidence in simulated concentrations has been achieved, the Airviro Scenario module can be used to combine the dispersion model results with demographic data to assess the health effect on the population. For Sweden this means the use of high resolution population data with $100 \times 100 \mathrm{~m}$ grid, separated into age intervals of 5 years. The Scenario module can handle health outcomes of long-term exposure, either mortality or the incidence of different diagnosis like cardiovascular or respiratory diseases. Concentration-response relationships should be taken from epidemiological studies published internationally. The present study has assessed the relative risk of mortality (the risk of dying in exposed population compared to the risk of dying in non-exposed population) due to PM2.5 particles and the concentration-response relationship was set to 1.17 per $10 \mu \mathrm{g} / \mathrm{m} 3$ [12].

The calculations were performed for three different locations in northern Sweden close to the city Umeå (63.8N, 20.3E): the villages Vännäs (population 6062), Sävar (population 2976) and the city Umeå (population 90230). Air quality parameters of particles - PM2.5 and sot, polyaromatic hydrocarbons, elementary carbon and black carbon - were measured in four different places and used for validation.

The emissions were estimated from chimney sweeps registers, including detailed data for about 3700 wood boilers and about 16900 stoves. Heating habits and wood consumption were estimated from interviews in 176 houses using a standardized form.

\section{$4 \quad$ Results and Discussion}

Figure 4 shows measured and modelled local daily mean concentrations of PM2.5 $\left(\mu \mathrm{g} / \mathrm{m}^{3}\right)$ from residential wood combustion in Sävar. The local contribution of the measurement is estimated as the difference between the measured local concentrations and the background concentration. In average the local contribution in Sävar is small, about $2 \mu \mathrm{g} / \mathrm{m}^{3}$. The daily variations are large, some days the local contribution can be higher than $10 \mu \mathrm{g} / \mathrm{m}^{3}$. These variations are typical for residential wood combustion in Sweden. As shown in the figure the model can reproduce these variations and the long term average rather well.

The results of the health impact assessment are summarised in Table 1 . The calculated maximum concentrations due to wood combustion vary between 2 and $4 \mu \mathrm{g} / \mathrm{m} 3$ while the traffic in the regional capital Umeå contributes up to $6 \mu \mathrm{g} / \mathrm{m} 3$. 

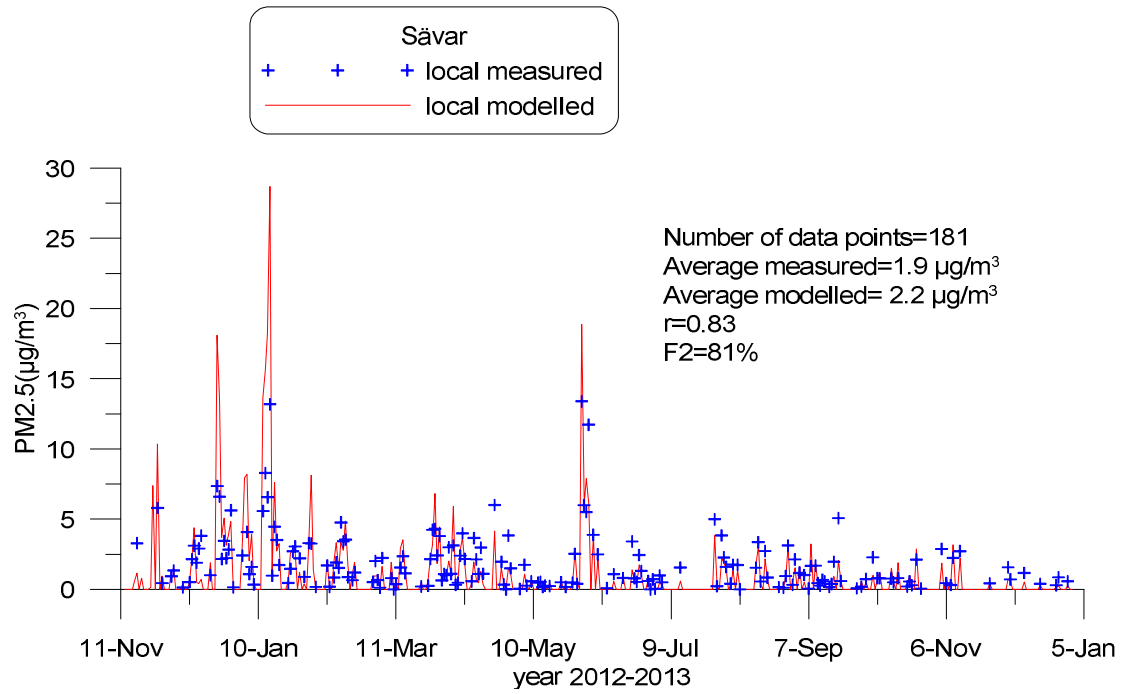

Fig. 4. Comparison of measured (blue cross) and modelled (red line) local daily mean PM2.5 concentrations $\left(\mu \mathrm{g} / \mathrm{m}^{3}\right)$ at Sävar. $r$ is the correlation coefficient and F2 denotes fraction of calculated concentrations that are within a factor of two of the measured concentrations.

The calculated population averaged concentrations due to wood combustion vary between $0.2-0.9 \mu \mathrm{g} / \mathrm{m} 3$ and are higher in the villages Vännäs and Sävar than in the city Umeå. This is due to the fact that extensive district heating system is used in Umeå but not in the two villages. The fraction of households using wood for residential heating is therefore much lower in Umeå where most wood stoves are used primarily for comfort and well-being and not as the main source of heating the house. This is also seen in the exposure histogram Figure 5.

Table 1. Summary of results from the calculations of annual mean concentrations, exposure and health impact

\begin{tabular}{|l|l|c|c|c|c|}
\hline \multirow{2}{*}{ Location } & source type & \multicolumn{2}{|c|}{$\begin{array}{c}\left.\text { PM2.5( } \mathbf{\mu g} / \mathbf{m}^{3}\right) \mathbf{y e a} \\
\text { rly mean }\end{array}$} & \multicolumn{2}{|c|}{$\begin{array}{c}\text { Health Impact } \\
\text { Assessment }\end{array}$} \\
\cline { 3 - 6 } & & Max & $\begin{array}{c}\text { Population } \\
\text { average }\end{array}$ & $\begin{array}{c}\text { Population } \\
\text { (number } \\
\text { of people }\end{array}$ & $\begin{array}{c}\text { Mortality } \\
\text { (number of } \\
\text { people/year) }\end{array}$ \\
\hline Umeå & local wood comb. & 2.38 & 0.165 & 90230 & 2.50 \\
\hline Umeå & local traffic & 6.20 & 0.295 & 90230 & 4.40 \\
\hline Vännäs & local wood comb. & 2.47 & 0.913 & 6062 & 0.93 \\
\hline Vännäsby & local wood comb. & 3.85 & 0.887 & 2976 & 0.44 \\
\hline
\end{tabular}

The estimated mortality due to PM2.5 concentrations from residential wood combustion for the summed population in the three locations of about 100000 people is about 4 persons/year, which corresponds to approximately $0.4 \%$ of the total number of deaths (excluding accidents). Scaling up this estimate to the whole population of 
Sweden, the estimated mortality due to PM2.5 from wood combustion is about 374 persons per year. This number can be compared with earlier estimates of about 100340 persons per year by Forsberg et al. [13] and about 216-282 persons per year by Brandt et al. [14] for Denmark. Scaling up the Danish estimate to the Swedish population, by the ratio between the Swedish and the Danish population i.e. 9.6/5.6, it means that the estimated mortality is about $370-483$ persons per year. The estimated mortality due to PM2.5 from local wood combustion in this project is thus close to earlier estimates in Sweden and Denmark.

For the Umeå population the traffic impact is higher (4.4 deaths per year) than the impact of wood combustion (2.5 deaths per year). Traffic impact was not assessed in the smaller cities, but it is obvious from Table 1 and Fig. 5 that wood combustion is there the dominating source contributing to PM2.5 exposure.

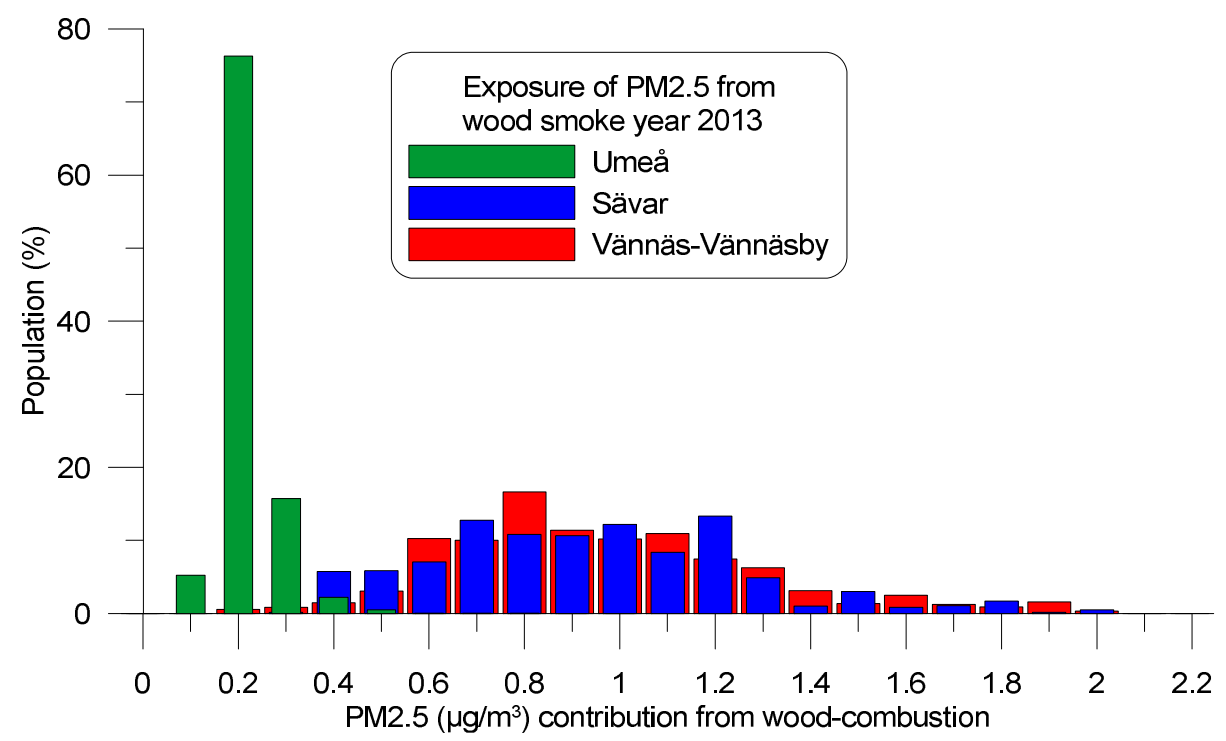

Fig. 5. Calculated number of persons (\%) that are exposed to locally generated PM2.5 from residential wood combustion in different concentrations intervals

The Airviro application presented, in which the impact of the two largest contributors to PM2.5 - traffic and residential wood combustion - have been assessed in urbanized areas with different characteristics, can easily be repeated for whatever city in Sweden. This because input data and model tools are available and updated each year, in order to allow the municipal authorities assess compliance to EU directive and Swedish environmental objectives. The concept behind the national modelling system SIMAIR can be summarized as making available on the web the Airviro software plus all input data:

- Use of Airviro software with all input provided for a first preliminary assessment in whatever Swedish location, i.e. long range transported contributions, urban contributions, local emissions and local meteorological information, all pre-stored as hourly data in a national database inside Airviro. 
- The municipal user just has to execute the local model to get a first preliminary result of total pollution concentrations, separated in different contributions. By reviewing and adjusting the local data that he or she are best suited to deliver, i.e. local traffic intensities, share of heavy duty vehicles etc., improved impact assessments are made for traffic environments. Similar improvements in wood combustion areas can be made with access to local chimney-sweeper data and interviews/questionnaires on wood consumption.

As for health impact studies this can also be done by external users, however experiences show that a health impact assessment require some training and understanding of epidemiological concentration-response relationships. Potential users of the health impact module are found at the regional health authorities rather than at individual municipalities.

\section{Conclusions}

The Airviro modeling system with the health impact calculation Scenario module has been used to assess the number of premature deaths from residential wood burning in the northern part of Sweden. In a summed population of 100000 inhabitants, local wood combustion is estimated to cause about 4 premature deaths per year, which is about $0.4 \%$ if the total number of deaths in this area. The fraction of the population exposed to large pollution contributions due to residential wood combustion is smaller in the city of Umeå compared to the neighboring villages, this since district heating is available to almost all residences in Umeå, but not in the same degree in the other two villages. However, for the Umeå population the traffic impact is higher with 4.4 deaths per year, as compared to wood combustion which there contributes with 2.5 deaths per year.

The advantages of using the web based Airviro software in combination with annually up-dated databases for input data on the national scale have been described. The approach facilitates for municipal end users and non-meteorological professionals like epidemiologists to perform by themselves advanced dispersion simulations and health impact assessments.

\section{References}

1. Lim, S.S., et al.: A comparative risk assessment of burden of disease and injury attributable to 67 risk factors and risk factor clusters in 21 regions, 1990-2010: a systematic analysis for the Global Burden of Disease Study. The Lancet, 380, 9859, 2224-2260 (2012)

2. Health Effects Institute, Ambient air pollution among top global health risks in 2010 (2013), http: / /www. heal theffects.org/International/GBD-PressRelease.pdf

3. WHO, Review of evidence on health aspects of air pollution - REVIHAAP Project, Technical report, 280 p. (2013) 
4. Genberg, et al.: Light-absorbing carbon in Europe - measurement and modelling, with a focus on residential wood combustion emissions. Atmos. Chem. Phys. 13, 8719-8738 (2013), doi:10.5194/acp-13-8719-2013

5. Gidhagen, L., Johansson, H., Omstedt, G.: SIMAIR - Evaluation tool for meeting the EU directive on air pollution limits. Atmospheric Environment 43, 1029-1036 (2009)

6. Omstedt, G., Andersson, S., Gidhagen, L., Robertson, L.: New model tools for meeting the targets of the EU Air Quality Directive: description, validation and evaluation of local air quality improvement due to reduction of studded tyre use on Swedish roads. Int. J. Environment and Pollution 47(1/2/3/4), 79-96 (2011)

7. http://www.smhi.se/airviro

8. Gidhagen, L., Omstedt, G., Pershagen, G., Willers, S., Bellander, T.: High resolution modeling of residential outdoor particulate levels in Sweden. J. Expos. Sci. \& Environ. Epidem., 1-9 (2013), doi:10.1038/jes.2012.122

9. Willers, S., Eriksson, C., Gidhagen, L., Nilsson, M.E., Pershagen, G., Bellander, T.: Fine and coarse particulate air pollution in relation to respiratory health in Sweden. Eur. Resp. J. 42, 924-934 (2013), doi:10.1183/09031936.00088212

10. Denzer, R., Schlobinski, S., Gidhagen, L., Hell, T.: How to Build Integrated Climate Change Enabled EDSS. In: Hřebíček, J., Schimak, G., Kubásek, M., Rizzoli, A.E. (eds.) ISESS 2013. IFIP AICT, vol. 413, pp. 464-471. Springer, Heidelberg (2013)

11. U.S. EPA.Environmental Benefits Mapping and Analysis Program (BenMAP), http: / / www .epa.gov/airquality/benmap/index.html

12. Jerrett, M., et al.: Spatial Analysis of Air Pollution and Mortality in Los Angeles. Epidemiology 16(6), 727-736 (2005)

13. Forsberg, B., Hansson, H.C., Johansson, C., Areskoug, H., Persson, K., Järvholm, B.: Comparative health assessment of local and regional particulate air pollutants in Scandinavia. Ambio 34, 11-19 (2005)

14. Brandt, J., Silver, J.D., Christensen, J.H., Andersen, M.S., Bonlokke, J.H., Sigsgaard, T., Geels, C., Gross, A., Hansen, A.B., Hansen, K.M., Hedegaard, G.B., Kaas, E., Frohn, L.M.: Contribution from ten major emission sectors in Europe and Denmark to the healthcost externalities of air pollution using the EVA model system - an integrated modelling approach. Atmos. Chem. Phys. 13, 7725-7746 (2013) 